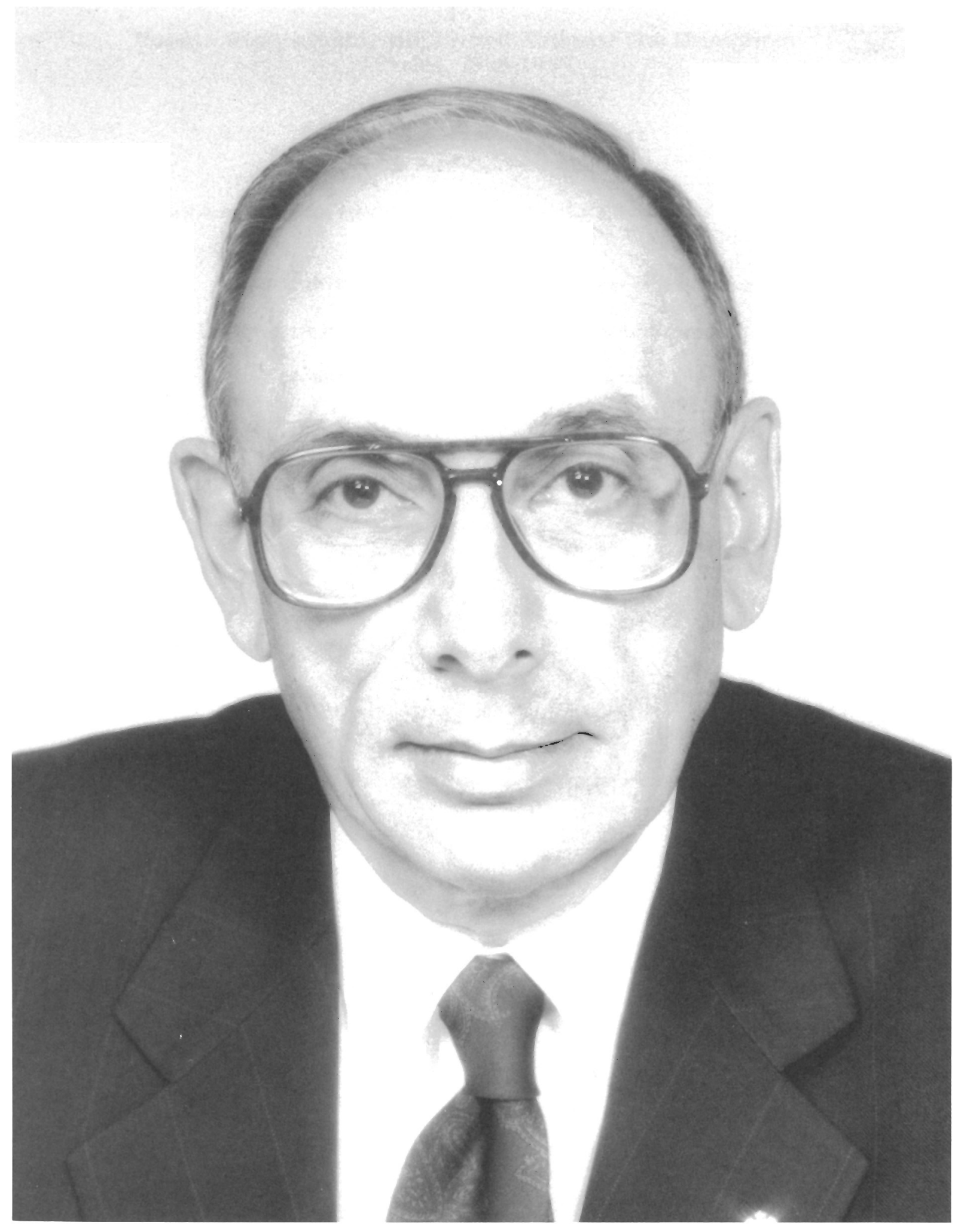




\section{Dedication to Dr. Samuel O. Freedman}

This, the fourth volume of Fontanus, is dedicated in honour of Dr. Samuel O. Freedman, Vice-Principal (Academic), McGill University, for the past ten years.

It is especially appropriate to dedicate this volume to Dr. Freedman, for no Academic VicePrincipal in memory has devoted so much generous attention to the betterment of our libraries. Dr. Freedman leaves our libraries in a far superior condition to what he encountered ten years ago. All of us owe him a sincere debt of appreciation.

It is hardly possible in a brief preface to enumerate all the manifold ways in which Dr. Freedman has sought to improve library services and collections, but 1 wish to emphasize a few of the most significant. Thanks to Dr. Freedman's farsightedness the McGill University Libraries now offer a highly sophisticated and virtually complete automation of services. Automated circulation is the most conspicuous of these services, but perhaps even more significant and enduring is the creation of the automated catalogue itself, McGill's MUSE database. This database, now comprising well over a million separate records and accessible not only by author and title but by subject, keyword, and Boolean search, has been a major achievement. Dr. Freedman deserves much of the credit for this, since he saw from the inception of automation that the conversion of catalogue records from written cards to electronic format-the "Recon" project-had to occur simultaneously with the installation of the Notis system. As a result, while Notis was being implemented, many thousands of records were also being converted; this was a courageous decision for it meant a certain delay in the provision of very visible public services (such as circulation) in favour of the superior on-line catalogue, which we now enjoy.

The automation of our libraries was but one of a number of projects and concerns which Dr. Freedman has overseen during his tenure as Academic Vice-Principal. His deep and abiding committment to the library's collections, weakened by inflation and reduced budgets, has been crucial. Thanks to Dr. Freedman's efforts, a substantial portion of monies raised during the last McGill Advancement Program was set aside for both retrospective and current acquisitions. These funds, and most particularly the rattrapage funds, have made an enormous difference, permitting the Library to undo some of the damage of the last 15 years.

Dr. Freedman's dedication to the highest standards of research and scholarship has had a huge impact, not only in faculties but in the libraries as well. He has championed the right of professional librarians to be full academic staff members and has steadfastly encouraged research projects and sabbatic leaves by librarians. In so doing, he has made the McGill University Library a challenging and inspiring place in which to work. All of us, librarians and library assistants, are sincerely grateful for his constant interest and encouragement.

It is, of course, especially fitting in this light to offer the present volume of Fontanus in Dr. Freedman's honour, for he has from the beginning supported the creation of a journal of scholarly research based on McGill collections. As chairman of the Fontanus Management Committee, Dr. Freedman has lent his insight and discernment to the continuance and development of this journal, devoted to the exploration of collections in libraries, archives and musuems of McGill University.

Despite budgetary constraints and bureaucratic debacles, Dr. Freedman has been not merely a superb administrator but a genuine friend of libraries, learning, and scholarship. His leadership over the past decade has been an inspiration to all of us. While we wish him every success in his new position as Professor of Medicine and Director of Research at the Sir Mortimer B. Davis Jewish General Hospital, we would like this fourth volume of Fontanus to serve as a visible and lasting acknowledgement of the appreciation and friendship which Dr. Freedman has inspired during his tenure as Academic Vice-Principal. 